Rakenteiden Mekaniikka

Vol. 50, Nro 3, 2017, s. 211-215

https://rakenteidenmekaniikka.journal.fi/index

https:/doi.org/10.23998/rm.64921

(CKirjoittaja(t) 2017.

Vapaasti saatavilla CC BY-SA 4.0 lisensioitu.

\title{
Ratapenkereen värähtelyriski nopeuden noustessa
}

\author{
Pekka Salmenperä ${ }^{1}$, Robert Hildebrand ja Riku Varis
}

Tiivistelmä. Tässä artikkelissa käsitellään värähtelyn kasvamisen riskiä radan nopeusrajoituksen noston yhteydessä Ylivieska-Liminka rataosalla mittaamalla kriittisimmäksi arvioidussa kohteessa ratapenkereen käyttäytymistä. Työssä selvitettiin ratarakenteessa etenevien oleellisten ja suurienergisten Rayleigh -aaltojen nopeuksia ratapenkereessä. SASW - analyysin mukaan ratapenkereen värähtely alkaa kasvaa merkittävästi nopeuksista 240 km/h ylöspäin.

Avainsanat: SASW, pengervärähtely, rautatie

Vastaanotettu 15.6.2017. Hyväksytty 10.8.2017. Julkaistu verkossa 21.10.2017.

\section{Johdanto}

Junakaluston nopeuden noston on todettu 1990-luvulta lähtien monessa kansainvälisessä tutkimuksessa aiheuttavan ratarakenteen värähtelyn kasvua [1, 2, 3, 4]. Tämä värähtely ilmenee voimakkaimmin palautuvan pystysuuntaisen siirtymän voimakkaana kasvuna. Tämä kasvu selittyy alhaisella aallonnopeudella pehmeikköjen pohjamaassa, joka kaluston nopeuden kasvaessa aiheuttaa kumuloituvaa siirtymää. Kriittiseksi junannopeudeksi kutsutaan arvoa, jossa pystysuuntainen värähtely voimistuu merkittävästi. Liiallinen värähtely tai palautuva painuma ratarakenteessa voi tuhota radan komponentteja tai lähialueen infrastruktuuria.

Mittauspisteeksi valittiin esiselvityksen perusteella pehmeikkö, jossa kartoitettiin olevan suurin värähtelyriski sillä rataosalla, jolla suuret nopeudet toteutuvat. Tässä kohteessa suoritettiin maassa etenevän värähtelyn aallonnopeuden mittauksia. SASW menetelmällä pyrittiin määrittämään pinta-aallonnopeuksia ratarakenteen eri kerroksissa. Suurin osa värähtelyenergiasta sitoutuu pinta-aaltoihin, joten ne olivat erityisen tarkastelun kohteena. Lisäksi ne ovat hitaampia kuin puristus- tai leikkausaallot, ja epämieluisassa tilanteessa kaluston nopeus voi lähestyä hitaimpien aaltojen nopeutta. Tämä tiedetään ulkomaisista tutkimuksista, joissa on havaittu ratapenkereen värähtelyn

${ }^{1}$ Vastuullinen kirjoittaja. pekka.salmenpera@tut.fi 
ja palautuvan painuman kasvavan, kun junan nopeus saavuttaa $60 \%$ tai enemmän pintaaaltojen nopeudesta [5]. Tämän jälkeen painuma kasvaa eksponentiaalisesti kriittiseen nopeuteen eli pinta-aallon nopeuteen asti.

\section{Ilmiön taustaa}

Tiedetään, että raideliikenteessä on olemassa kaksi kriittistä nopeutta, jolloin värähtely voimistuu: Kiskojen taivutusjäykkyyden ja raiteen sekä penkereen massan ja maaperän ominaisuuksien määrittämä kriittinen nopeus sekä usein matalampi, maassa etenevien Rayleigh-aaltojen (R-aallot) nopeus [1, 4]. Maan värähtelyssä tapahtuu merkittävä voimistuminen, jos junan nopeus ylittää maassa etenevien R-aaltojen nopeuden. Tähän viitataan usein termillä "ground vibration boom" [6]. Ilmiö voidaan rinnastaa tilanteeseen, jossa lentokone ylittää äänivallin, jolloin ääniaallot muodostavat auramaisen Mach-aallon äänilähteen liikkuessa nopeammin kuin ääniaallot ilmassa [7].

Ensimmäisen kerran värähtelyn voimistuminen kriittisen nopeuden ylittämisen seurauksena havaittiin lokakuussa 1997 Ruotsissa, Göteborg-Malmö-rataosuudella Ledsgårdin lähellä [8]. Kuitenkin jo vuonna 1993 tehdyt mittaukset Britanniassa osoittivat junan nopeuden kasvattamisen lisäävän värähtelyä [3]. Myös Suomessa on havaittu, että ratapenkereen yläpinta alkaa värähdellä pystysuunnassa voimistuvasti junan nopeuden lähestyessä kriittistä nopeutta [9].

SASW on mittaus- ja analysointimenetelmä, jossa mitataan R-aaltojen nopeutta. Menetelmällä on mahdollista mitata R-aallon nopeutta noin yhden aallonpituuden syvyydelle, käytännössä noin 20-30 metriin asti. Mittaus tapahtuu sijoittamalla värähtelylähde sekä vähintään 2 geofonia maanpinnalle ja mittaamalla pinta-aallon etenemisnopeuksia vastaten eri taajuuksia tai taajuuksien vaihdellessa, jolloin saadaan tieto etenemisnopeuden vaihtelusta syvyyden mukaan. [10]

\section{Mittaukset}

SASW -menetelmä perustuu herätteen antamiseen maan pinnalle pystysuuntaan ja vasteen mittaamiseen maanpinnasta pystysuunnassa. Maaperässä etenevään liikkeeseen syntyy tällöin monia aallonnopeuksia, eri maalajeihin ja kerroksiin. Koska jokaisella aallonnopeudella on oma taajuutensa, niitä voidaan tutkia spektrianalyysilla. Ristispektrissä kahden anturin signaalin välillä näkyvä eri taajuuksien vaihe-ero osoittaa, kuinka paljon kyseisen taajuuden värähtely on muuttanut vaihettaan kahden eri mittapisteen välillä, kuva 1. Tästä voidaan laskea kyseisen taajuuden aallonpituus kun tiedetään muutosnopeus tietyllä välimatkalla. Kun lisäksi tiedetään, että aallonnopeus on taajuus kerrottuna aallonpituudella, voidaan kaikille eri taajuuksille laskea aallonnopeudet. SASW:n tuloksena saadaan siis kaikkien eri maakerrosten aallonnopeudet erikseen eri taajuuksien vaihe-erosta laskemalla. 


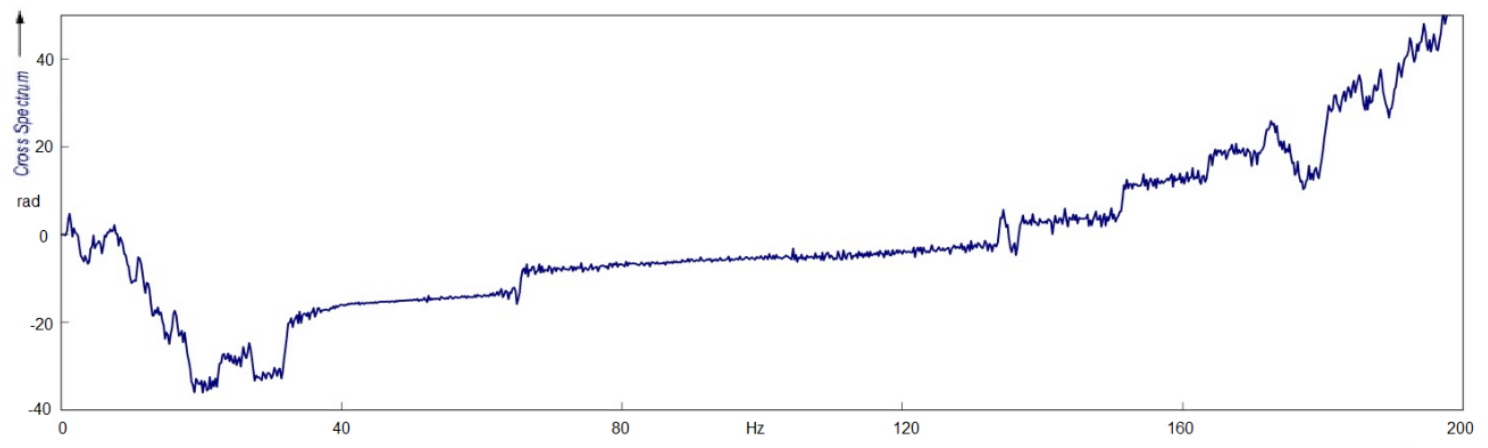

Kuva 1. Ristispektri SASW anturien signaalien välillä, josta nähdään eri taajuuksien väliset vaihe-erot.

SASW menetelmään kuuluu varmistaa mittaustulosten mittasignaalien laatu, jota voidaan arvioida koherenssifunktiolla mittasignaalien välillä [11]. Koherenssifunktio ei ollut riittävän hyvä alkuperäisissä signaaleissa. Koherenssifunktio osoittaa koherenssin arvon taajuuksien vaihteluvälillä 0-1. SASW:ssa vaadittu koherenssi on 0,95 tässä analyysissa, ja samaa raja-arvoa on käytetty myös muissa tutkimuksissa. Koherenssia ei saatu näin korkealle ilman keskiarvostusta, jonka vaikutus näkyy kuvien 2 ja 3 erona. Kuvassa 2 nähdään, miten koherenssi ei saavuta tätä arvoa kuin kapeilla taajuuskaistoilla. Keskiarvostuksella koherenssi saatiin kuitenkin nostetuksi riittävän korkealle taajuusalueilla 35-63 Hz sekä 67-110 Hz, kuva 3. Nämä taajuusalueet ovat myös hyviä perusoletuksia maaperän värähtelyjen taajuussisällölle. SASW menetelmässä taajuuskaistojen, joilla koherenssi ei ole riittävä, suodattamista tuloksista kutsutaan 'masking' operaatioksi.

Kuvassa 4 esitetään SASW mittauksen tulokset. Alhaisin aallonnopeusalue on 90-130 $\mathrm{m} / \mathrm{s}$, jonka keskiarvoksi saatiin $111 \mathrm{~m} / \mathrm{s}$. Ylemmät aallonnopeusalueet kuvaavat muiden radan kerrosten aallonnopeuksia. Alhaisimman aallonnopeuden alue vastaa kaluston nopeusaluetta $195-281 \mathrm{~km} / \mathrm{h}$, jolla palautuva painuman kasvu alkaa voimistua, keskiarvon ollessa $240 \mathrm{~km} / \mathrm{h}$.

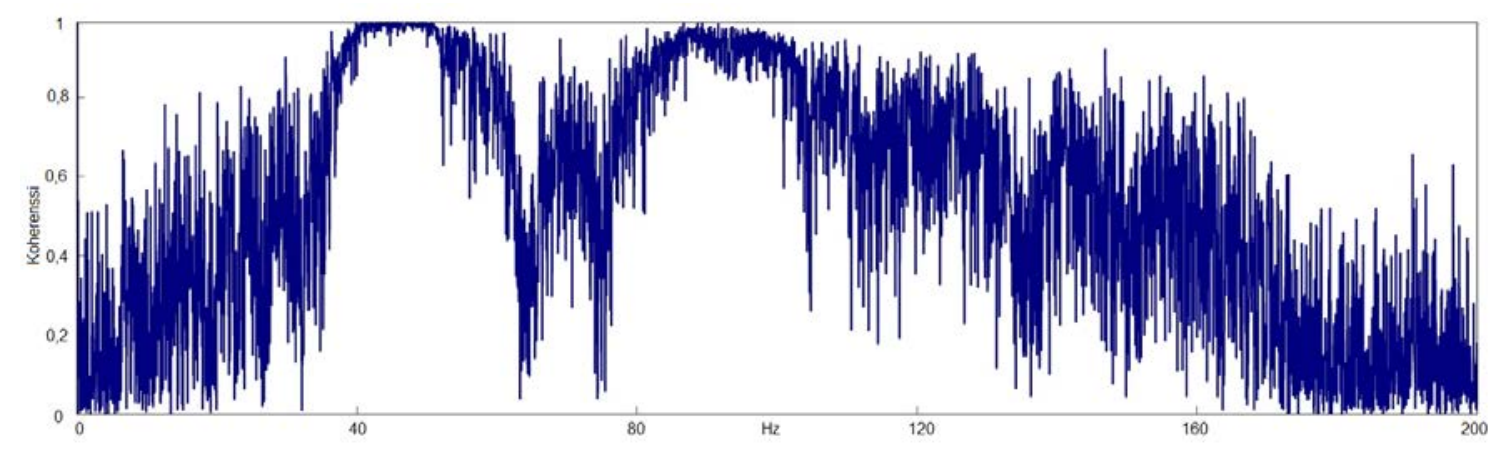

Kuva 2. SASW analyysin koherenssifunktio taajuusalueella 0-200 Hz ennen keskiarvostusta. 


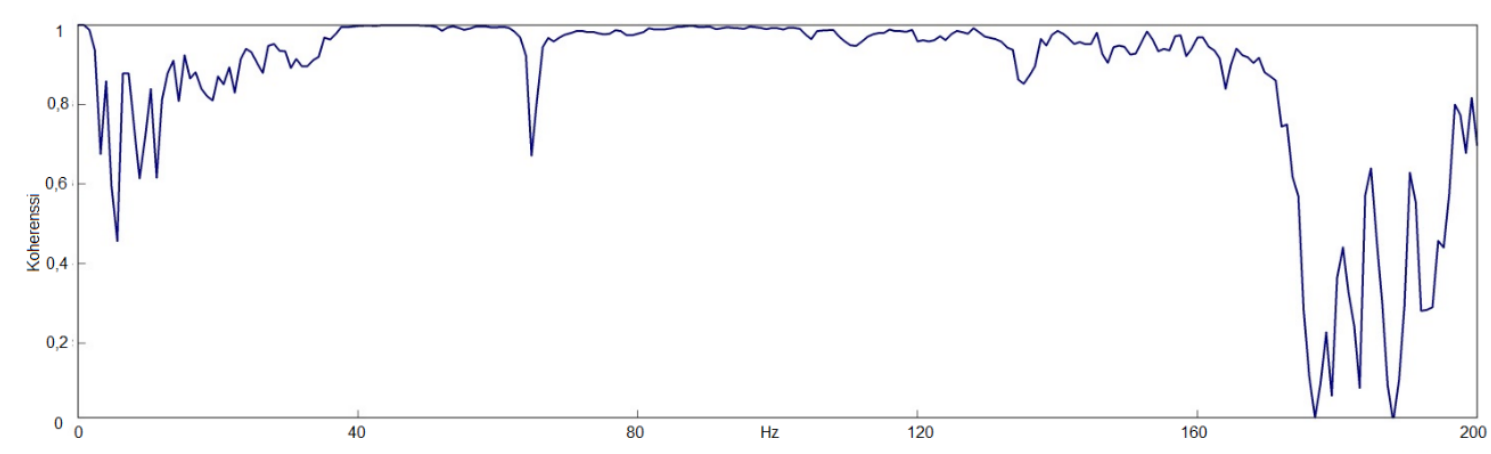

Kuva 3. SASW analyysin koherenssifunktio taajuusalueella 0-200 Hz 10 mittauksen keskiarvostuksen jälkeen.

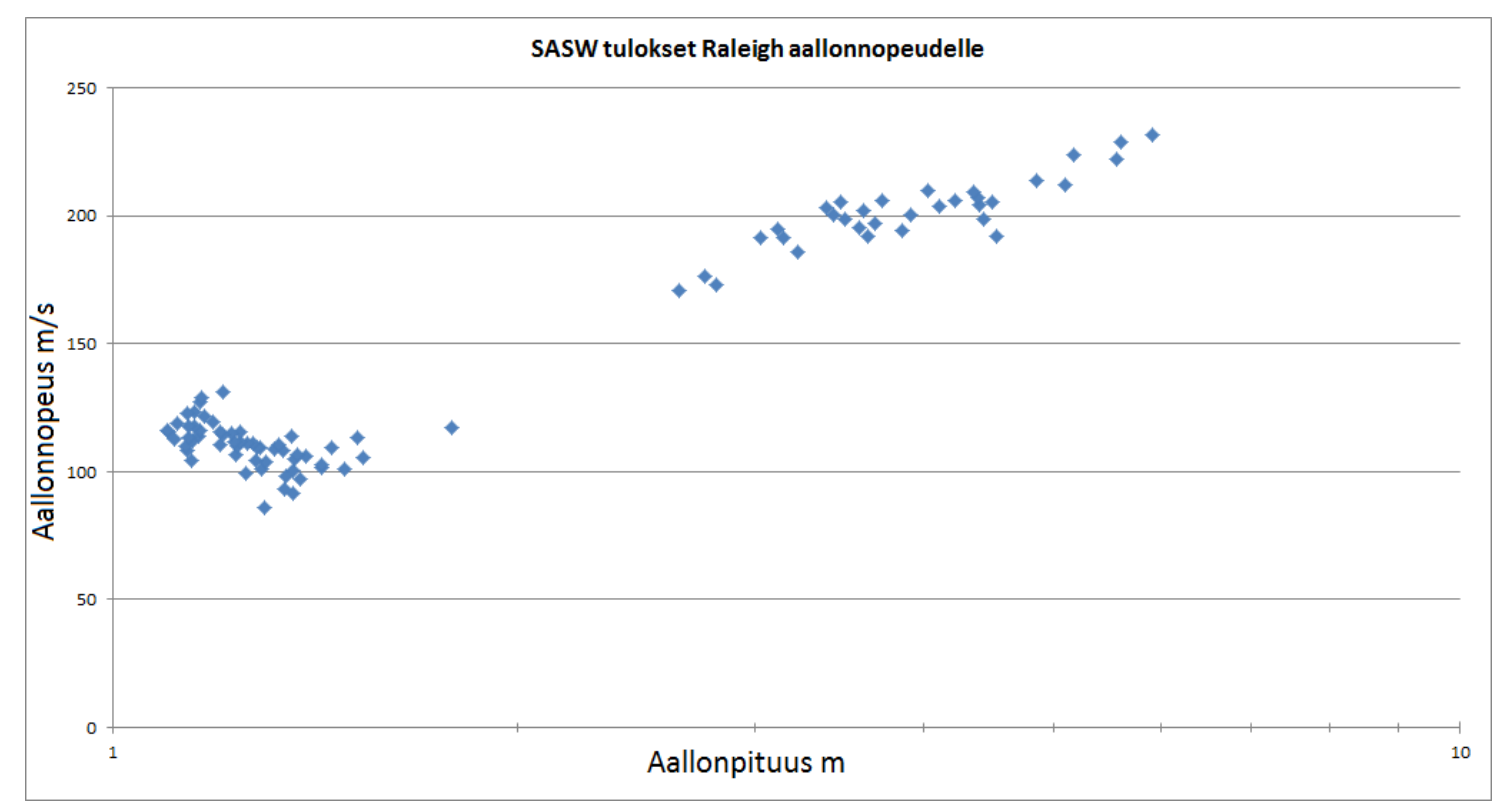

Kuva 4. SASW mittauksen tulokset ratarakenteen aallonnopeusjakaumalle.

Pehmeikön värähtelyn ja palautuvan painuman voidaan siis arvioida kasvavan merkittävästi pistejoukon keskiarvon mukaisesti nopeuden ollessa $240 \mathrm{~km} / \mathrm{h}$, taikka erittäin varovaisella arviolla alimman pisteen mukaisesti $195 \mathrm{~km} / \mathrm{h}$ nopeudesta ylöspäin. Koeajomittauksilla varmistettiin lisäksi, ettei värähtely eikä painuma kasva kriittiseksi liikennöintinopeuksissa.

\section{Viitteet}

[1] Krylov, V. V. (1995). Generation of ground vibrations by superfast trains. Applied Acoustics 44. pp.149-164. https://doi.org/10.1016/0003-682X(95)91370-I

[2] Banverket, Evaluation and analyses of measurements from the west coast line at Ledsgård, 1999. 
[3] Woldringh, R.F., New, B.M. (1999). Embankment design for high speed trains on soft soils. Geotechnical Engineering for Transportation Infrastructure, Barends et al. (eds).

[4] Madshus, C., Kaynia, A. M. (2000). High-speed railway lines on soft ground: dynamic behavior at critical train speed. Journal of Sound and Vibration 231(3). pp. 689-701. https://doi.org/10.1006/jsvi.1999.2647

[5] Törnqvist, J., Hakulinen, M., Koskinen, M. Nuutilainen, O. Ratapenkereen värähtelyn arviointi Seinäjoki - Oulu -rataosuudella. Tutkimusraportti, VTT. 2015.

[6] Krylov, V.V. (1994) On the theory of railway-induced ground vibrations, Journal de Physique IV. 4 (C5). pp. 769-772. https://doi.org/10.1051/jp4:19945167

[7] Massarsch, K. R., Bodare, A., Smekal, A. (2002). Effects of vibrations from railway traffic, PrognosVib Report 1, Delrapport 1, Contract B01-1027/17. Banverket. 111p. URL: www.georisk.se/getfile.ashx?cid=67228\&cc=3\&refid=47.

[8] Krylov, V.V. (2011) Comments on chapter 12 of "railway noise and vibration: mechanisms, modelling and means of control”, by D. Thompson (with contributions from C. Jones and P.-E. Gautier), Elsevier, 2009. Applied Acoustics 72 (2011). pp. 785-786. https://doi.org/10.1016/j.apacoust.2011.03.004

[9] Törnqvist, J. (2011). Lielahti-Seinäjoki rataosan pengervärähtely, VTT-R-0039010. VTT. 42s.

[10] Möller, B., Larsson, R., Bengtsson, P.-E., Moritz, L. (2000). Geodynamik i praktiken, Information 17. Statens Geotekniska Institut. 51 s. URL: http://www.swedgeo.se/upload/Publikationer/Info/pdf/SGI-I17.pdf

[11] Hildebrand R., Miettinen J., Montonen J., Raunisto Y. "Soil and building response to a compaction hammer and sheet piler," Soc Experimental Mechanics IMAC XXII, 2004, Dearborn, Michigan

Pekka Salmenperä

VR Track Oy

Rautatienkatu 25A, 33100 Tampere

pekka.salmenpera@vr.fi

Robert Hildebrand

Lake Superior State University

650 W. Easterday Ave., Sault Ste. Marie, MI 49783

rhildebrand@lssu.edu

Riku Varis

Tampereen teknillinen yliopisto

Korkeakoulunkatu 5, 33720 Tampere

riku.varis@tut.fi 